\section{David Bracco \\ Nicolas Noiseux \\ Thomas M. Hemmerling}

\title{
The thin line between life and death
}

Received: 29 January 2007

Accepted: 29 January 2007

Published online: 7 March 2007

(C) Springer-Verlag 2007

This editorial refers to the article available at: http://dx.doi.org/10.1007/s00134-007-0568-4

\author{
D. Bracco $(\bullet)$ - T. M. Hemmerling \\ McGill University, Department of Anesthesiology, Cardiac \\ Anesthesia, Montreal General Hospital, McGill University Health \\ Center, \\ 1650 Cedar Avenue, H3G 1A4 Montréal, Canada \\ e-mail: david.bracco@mcgill.ca \\ Tel.: +1-514-9341934 ext 43030 \\ Fax: +1-514-9348249

\section{N. Noiseux} \\ Montréal University Hospital, Department of Cardiac Surgery, \\ Organ Transplantation Team, Hôtel Dieu Hospital, \\ Montréal, Canada
}

Historically, death was defined by the irreversible cessation of breathing and pulse. This view has been challenged with the development of recent sophisticated life support techniques. It has been shown that the heart can be "restarted" after cardiac arrest and patients can be resuscitated. These developments are summarized in the recent updates of the guidelines of the European Resuscitation Council [1] and the American Heart Association [2]. Despite numerous studies, the blood flow generated during cardio-pulmonary resuscitation (CPR) is often insufficient to meet metabolic requirements, providing only very short-term support, and the probability of return of spontaneous circulation decreases rapidly. Every minute under CPR adds significant mortality and (neurologic) morbidity. So, despite advances in modern CPR technologies, outcome after CPR remains poor [3]. The transport of cardiac arrest victims under continuous
CPR is controversial [4], and outcome depends on various external factors [5].

Numerous strategies aiming at improving global blood flow during CPR or directing blood flow toward vital organs have been studied: although some animal studies have shown small improvements in outcome, no clinical breakthrough in humans has been achieved. There is also a gap between (theoretical) guidelines and daily practice, with numerous deviations during in-hospital [6] or pre-hospital [7] cardiac arrests. In this context, mechanical assist devices allowing uninterrupted and constant CPR have been developed, but have not routinely been used.

The ultimate goal of CPR would be to fully support the functions of the heart and lungs via an external mechanical system. Cardio-pulmonary bypass devices were introduced in cardiac surgery over 50 years ago, and are required for open-heart procedures [8]. The cardio-pulmonary bypass allows sufficient blood flow and oxygenation to the vital organs for several hours during a surgical procedure without jeopardizing cerebral functions. With the introduction of more biocompatible circuits and more reliable oxygenators, these devices can replace the heart and the lungs and support the metabolic requirements for many days.

Extra-corporeal life support (ECLS) devices have been previously applied during CPR by several authors [9, $10,11,12,13]$. One case report describes a 4-year-old boy undergoing CPR for 3 hours before extracorporeal membrane oxygenation (ECMO) was instituted; this child was discharged from the hospital with normal neurological function [12]. In the present issue of Intensive Care Medicine, Megarbane and co-workers [14] present their series of ECLS during refractory cardiac arrest. The authors should be congratulated for their efficient set-up, their collaboration with an adjacent cardiac surgical team and the ethical guidelines they seek for this intervention. However, their results should be carefully read: out of some 180 patients arriving in cardiac arrest at their institu- 
tion during the 2 years of observation (about 90 per year), 17 patients were eligible for ECLS, 14 patients received effective ECLS after a mean of $2 \mathrm{~h}$ of CPR, 7 patients survived at $24 \mathrm{~h}$ and 3 patients were discharged alive from the hospital without neurologic deficit. Obviously, for the three patients discharged without sequel from the hospital, this is $100 \%$ survival in a setting with a predicted 99.9999\% mortality. The authors had no survivor with post-anoxic neurologic deficit, showing that the blood flow provided during CPR and ECLS was sufficient to maintain brain neuronal integrity. The patients were included in a strict protocol, approved by an institutional review committee, for refractory cardiac arrest due to membrane-stabilizing drug poisoning. Their patient cohort slightly expanded the original indication by including pulmonary embolism, amniotic fluid embolism and various others causes of cardiac arrest. The only survivors were from the group of patients with cardiac arrest due to membrane-stabilizing drugs; no survival was recorded in the extended indications group. The authors used ECMO as a support technique in patients with massive pulmonary embolism and thrombolysis, whereas other researchers proposed ECMO as a bridge to surgical embolectomy in massive pulmonary embolism [15].

Several technical aspects of ECLS during cardiac arrest deserve comment: Firstly, femoro-femoral cannulation has inherent risks. Although it is not a technically difficult procedure for trained cardiac or vascular surgeons, there is always the risk of vascular trauma. Starting the CPB with the arterial cannula in an arterial flap is almost fatal within minutes. An inferior vena cava laceration can equally have disastrous consequences. Even in the desperate context of unsuccessful CPR, these techniques should be performed exclusively by trained surgeons in an appropriate environment and support.

A second important consideration is anticoagulation: We agree with Megarbane and colleagues that the circuits have been greatly improved in terms of biocompatibility and pro-inflammatory reactions, and we also noted that the patients had a disturbed coagulation profile. However, is it prudent to start $\mathrm{CPB}$ without anticoagulation or at least an anticoagulated prime solution? It can be argued that heparin will circulate badly or not at all in a patient during CPR conditions, but priming the pump with at least $100-150 \mathrm{mg}$ heparin might be advisable. Massetti, in a similar setting, primed the circuit and the patient with heparin [16], whereas Schwarz administered 40-80 U/kg heparin to the patient [13].

A third consideration concerns venous return and left heart decompression [17]. In the study by Megarbane and co-workers, there were a significant proportion of patients with massive capillary leak $(n=5)$, hemorrhagic pulmonary edema $(n=6)$, and bleeding $(n=8)$. A possible drawback of ECLS is that the left ventricle cannot eject into the aorta due to an increased afterload with blood re-injected by the pump into the aorta. In these conditions, with competent mitral and aortic valves, there is a massive left atrial and pulmonary venous congestion, which can cause pulmonary capillary stress failure and hemorrhagic pulmonary edema. This phenomenon is directly dependent on the venous return via the venous cannula, which is suboptimal in venous femoral ECLS. Hemodilution and/or anticoagulation might help in these settings, but femoral venous access is limited in terms of cardiac decompression. Some investigators [18, 19] propose a trans-septal left atrial decompression built into the ECLS circuit. The authors also tried to improve left ventricular decompression by keeping the patient on dobutamine; however, the effect of dobutamine on a heart 'poisoned' by a membrane-stabilizing drug is not known.

The skills required to efficiently use ECMO are very difficult to acquire and maintain in an intensive care unit (ICU). Although there is no defined minimal practice number in the literature, we strongly discourage implementation of these techniques without the support and backup of cardiac surgeons and perfusionists. There are convincing data from the UK collaborative study that ECMO is (cost-) effective in neonatal support [20,21], but there is no such agreement for adult ECMO. There are no studies showing cost-effectiveness of ECLS in cardiac arrest. It is interesting to note that the authors invested a significant amount of money and effort in developing and implementing ECMO in a non-cardiac surgical center.

Despite more sophisticated techniques in the ICU, a significant number of patients develop irreversible neurological failure. This has led to the need for further refinement in the diagnosis of brain death, and the development of organ donation programs. Most countries actually have clear definitions of brain death, laid down as complete and irreversible loss of all brain and brain stem function. As the number of patients requiring organ transplantations is growing faster than the number of available organs, alternative sources for organ procurement are discussed. In contrast to organ donation after brain death, organ donation after cardiocirculatory arrest and death is defined as the surgical recovery of organs after the pronouncement of death based on cessation of cardiopulmonary function [22]. Organ donation after cardiac death (DCD) can be divided into two categories on the basis of the process and timing of the organ recovery: controlled and uncontrolled organ donation [22].There are new developments in this field with the use of non-heartbeating donors for kidney [23], liver [24, 25] and lung [26] transplantations. In controlled DCD, once the decision to withdraw life support is made with consent, withdrawal occurs in a progressive and controlled fashion. Then, organ procurement is performed in the operating room. In uncontrolled DCD, the patient is considered as a potential donor only when cardiac arrest is irreversible or when the lesions provoking the cardiac arrest are incompatible with life [23]. The team of Madrid's Hospital Clinico San Carlos recently published a case series including harvesting 
kidneys from patients after cardiac arrest occurring outside the hospital. CPR was continued until achievement of in situ organ preservation by femoro-femoral perfusion using extra-corporeal circulation with external oxygenation and hypothermia [27]. While the organs are perfused, the transplant coordination team takes care of the legal requirements for organ donation. Intensive care practitioners do not feel comfortable and are very reluctant to accept and support organ donation after cardiac death [28].

The front-line clinician faces a difficult ethical dilemma: Who will decide - and based on which criteria - that patient A arriving in the emergency department under CPR will go to the operating room (or any adequate location) for femoro-femoral cannulation and ECLS in the attempt to reverse the cause of the cardiac arrest [14] and that patient B arriving at the same emergency department under CPR will undergo femoro-femoral cannulation for in situ perfusion and organ harvesting? Where is the line between refractory cardiac arrest making the patient a potential candidate for ECLS - and irreversible cardiac arrest - making the patient a potential organ donor? Megarbane and co-workers used the term refractory cardiac arrest to put the patients on rescue ECLS; Sanchez-Fructuoso [23] harvested kidneys from irreversible cardiac arrest patients; and Massetti entitled their case series of ECLS in cardiac arrest "Back from irreversibility" [16].

The use of ECLS in the context of CPR seems to have better results as a support technique for cardiac arrest due to cardio-toxic drugs or hypothermia [2, 29, 30]. It could also be considered as a bridge to surgery in massive pulmonary embolism. For the successful implantation of ECLS in cardiac arrest, the active involvement of cardiac surgeons and perfusionists seems quintessential. Centers aiming to implement ECLS for refractory cardiac arrests and/or non-heart-beating organ donor programs should clearly define the settings of femoro-femoral perfusion. The thin line between life and death, between rescue ECLS and in situ organ perfusion, must be clearly defined before these techniques can be more widely used.

\section{References}

1. de Latorre F, Nolan J, Robertson C, Chamberlain D, Baskett P (2001) European Resuscitation Council Guidelines 2000 for Adult Advanced Life Support. A statement from the Advanced Life Support Working Group(1) and approved by the Executive Committee of the European Resuscitation Council. Resuscitation 48:211-221

2. American Heart Association (2005) Guidelines for advanced cardiac life support. Circulation 112(Suppl 4):1-211

3. De Maio VJ, Stiell IG, Spaite DW, Ward RE, Lyver MB, Field BJ 3rd, Munkley DP, Wells GA (2001) CPR-only survivors of out-ofhospital cardiac arrest: implications for out-of-hospital care and cardiac arrest research methodology. Ann Emerg Med 37:602-608

4. Pepe PE, Swor RA, Ornato JP, Racht EM, Blanton DM, Griswell JK, Blackwell T, Dunford J (2001) Resuscitation in the out-of-hospital setting: medical futility criteria for on-scene pronouncement of death. Prehosp Emerg Care 5:79-87

5. Hick JL, Mahoney BD, Lappe M (1998) Factors influencing hospital transport of patients in continuing cardiac arrest. Ann Emerg Med 32:19-25

6. Abella BS, Alvarado JP, Myklebust H, Edelson DP, Barry A, O'Hearn N, Vanden Hoek TL, Becker LB (2005) Quality of cardiopulmonary resuscitation during in-hospital cardiac arrest. JAMA 293:305-310
7. Wik L, Kramer-Johansen J, Myklebust H, Sorebo H, Svensson L, Fellows B, Steen PA (2005) Quality of cardiopulmonary resuscitation during out-of-hospital cardiac arrest. JAMA 293:299-304

8. Cohn LH (2003) Fifty years of open-heart surgery. Circulation 107:2168-2170

9. Younger JG, Schreiner RJ, Swaniker F, Hirschl RB, Chapman RA, Bartlett RH (1999) Extracorporeal resuscitation of cardiac arrest. Acad Emerg Med 6:700-707

10. Chen YS, Chao A, Yu HY, Ko WJ, Wu IH, Chen RJ, Huang SC, Lin FY, Wang SS (2003) Analysis and results of prolonged resuscitation in cardiac arrest patients rescued by extracorporeal membrane oxygenation. J Am Coll Cardiol 41:197-203

11. Jaski BE, Lingle RJ, Overlie P, Favrot LK, Willms DC, Chillcott S, Dembitsky WP (1999) Long-term survival with use of percutaneous extracorporeal life support in patients presenting with acute myocardial infarction and cardiovascular collapse. ASAIO J 45:615-618

12. Kelly RB, Porter PA, Meier AH, Myers JL, Thomas NJ (2005) Duration of cardiopulmonary resuscitation before extracorporeal rescue: how long is not long enough? ASAIO J 51:665-667
13. Schwarz B, Mair P, Margreiter J, Pomaroli A, Hoermann C, Bonatti J, Lindner KH (2003) Experience with percutaneous veno-arterial bypass for emergency circulatory support. Crit Care Med 31:758-764

14. Megarbane B, Leprince P, Deye N, Résière $\mathrm{D}$, Guerrier $\mathrm{G}$, Rettab $\mathrm{S}$, Théodore J, Karyo S, Gandjbakhch I, Baud F (2007) Emergency feasibility in medical intensive care unit of extracorporeal life support for refractory cardiac arrest. Intensive Care Med DOI 10.1007/s00134-007-0568-4

15. Deehring R, Kiss AB, Garrett A, Hillier AG (2006) Extracorporeal membrane oxygenation as a bridge to surgical embolectomy in acute fulminant pulmonary embolism. Am J Emerg Med 24:879-880

16. Massetti M, Tasle M, Le Page O, Deredec R, Babatasi G, Buklas D, Thuaudet S, Charbonneau P, Hamon M, Grollier G, et al (2005) Back from irreversibility: extra-corporeal life support for prolonged cardiac arrest. Ann Thorac Surg 79:178-183

17. Hanna BD (2006) Left atrial decompression: Is there a standard during extracorporeal support of the failing heart? Crit Care Med 34:2688-2689

18. Aiyagari RM, Rocchini AP, Remenapp RT, Graziano JN (2006) Decompression of the left atrium during extracorporeal membrane oxygenation using a transseptal cannula incorporated into the circuit. Crit Care Med 34:2603-2606 
19. Johnston TA, Jaggers J, McGovern JJ, O’Laughlin MP (1999) Bedside transseptal balloon dilation atrial septostomy for decompression of the left heart during extracorporeal membrane oxygenation. Catheter Cardiovasc Interv 46:197-199

20. Mielck F, Quintel M (2005) Extracorporeal membrane oxygenation. Curr Opin Crit Care 11:87-93

21. Petrou S, Bischof M, Bennett C, Elbourne D, Field D, McNally H (2006) Cost-effectiveness of neonata extracorporeal membrane oxygenation based on 7-year results from the United Kingdom Collaborative ECMO Trial. Pediatrics 117:1640-1649

22. Edwards J, Mulvania P, Robertson V, George G, Hasz R, Nathan H, D'Alessandro A (2006) Maximizing organ donation opportunities through donation after cardiac death. Crit Care Nurse 26:101-115
23. Sanchez-Fructuoso AI, Marques M, Prats D, Conesa J, Calvo N, PerezContin MJ, Blazquez J, Fernandez C, Corral E, Del Rio F, et al (2006) Victims of cardiac arrest occurring outside the hospital: a source of transplantable kidneys. Annals of internal medicine 145:157-164

24. White SA, Prasad KR (2006) Liver transplantation from nonheart beating donors. BMJ (Clinical Research edn) 332:376-377

25. Abt PL, Desai NM, Crawford MD, Forman LM, Markmann JW, Olthoff KM, Markmann JF (2004) Survival following liver transplantation from non-heart-beating donors. Ann Surg 239:87-92

26. Rega FR, Jannis NC, Verleden GM, Flameng WJ, Lerut TE, van Raemdonck DE (2003) Should we ventilate or cool the pulmonary graft inside the non-heart-beating donor? J Heart Lung Transplant 22:1226-1233
27. Balupuri S, Buckley P, Mohamad M, Chidambaram V, Gerstenkorn C, Sen B, Kirby J, Manas DM, Talbot D (2000) Early results of a non-heartbeating donor (NHBD) programme with machine perfusion. Transplant Int 13(Suppl 1):S255-S258

28. Mandell MS, Zamudio S, Seem D, McGaw LJ, Wood G, Liehr P, Ethier A, D'Alessandro AM (2006) National evaluation of healthcare provider attitudes toward organ donation after cardiac death Crit Care Med 34:2952-2958

29. Moser B, Voelckel W, Gardetto A, Sumann G, Wenzel V (2005) One night in a snowbank: a case report of severe hypothermia and cardiac arrest. Resuscitation 65:365-368

30. Jones AI, Swann IJ (1994) Prolonged resuscitation in accidental hypothermia: use of mechanical cardio-pulmonary resuscitation and partial cardio-pulmonary bypass. Eur J Emerg Med 1:34-36 